\title{
Freed or Trapped: Gaming Pleasures and Expression of Gender Identities in World of Warcraft among Chinese Players
}

\begin{abstract}
By Qiaolei Jiang *
Information communication technologies hold an ambivalent place for gender identities in cyber space. In this sense, the ways that online game players make meaning of, respond to, and take pleasure in gaming lead to insights into how online games might serve as spaces for the enactment of new forms of gender identities. This study focuses on a bourgeoning communication phenomenon concerning MMORPG. Through a case study of World of Warcraft (WoW) guided by Uses and Gratifications theory, the paper explores gaming (dis)pleasures and expression of gender identities. Based on the data collected from virtual ethnography, which mainly included participant observation and in-depth interviews of 22 WoW players, the study takes a snapshot of the ways in which gender identities are constructed in WoW. The findings show that diverse options seem not to lead to a corresponding mobility or fluidity in terms of how gender can be performed in the game, even with "ladyboy" as an interesting phenomenon in gameplay. The paper argues that players" preferences and orientations toward gendered characters reflect their interplay with gaming rules, dominant narratives and relationships in real life, as well as the enactment in role-playing and image-based interfaces. Although some female players have to derive pleasures from a male perspective, there are some alternative consumptions of the masculine genre like WoW.
\end{abstract}

Keywords: avatar, gender, identity, pleasure, uses and gratifications

\section{Introduction}

Digital entertainments, symbolized by online games, have become mainstream internationally. Online games have become a vital part of Chinese Netizens' lives since the introduction of Massively Multiplayer Online Role-Playing Games (MMORPG) in Mainland China in 2000. MMORPGs refer to the computer games that enable hundreds or thousands of players to interact simultaneously in a game world established via the Internet. Players are fascinated in the virtual world with their character avatars.

The number of Chinese Internet users has reached 731 million (CNNIC, 2017), which makes the Chinese online game market very attractive. In the total consumption of popular Internet services, online games currently constitute $57.0 \%$ (CNNIC, 2017). By the end of 2016, the number of online game players in China increased to 417 million (CNNIC, 2017). As for popularity, with a longstanding popular history around the world, World of Warcraft (WoW) has been among the top online games in China for many years (CNNIC, 2009). However, serious reflections on the popularity of WoW are still limited in China. Since the influence of online games is expanding, it is necessary to investigate the ins and outs of games. This study attempts to explore the uses and gratifications of MMORPG players, especially their gaming experiences related to gender issues. Through a case study, the paper attempts to map the expression of gender identities of players

*Associate Professor, Dalian University of Technology, China. 
driven by gaming pleasures in the context of $W o W$, and explore how players maintain balance between consuming online games as cultural products with features of a fantasy world and using role play to create their virtual social relationship, and even about how players' online activities are interwoven with their offline life.

\section{Literature Review}

Online game playing is experience-oriented. However, even with an increasing number of gaming studies, there are still not enough studies on players' multiple gaming pleasures and their experiences with identity expression (Wu, Wang, \& Tsai, 2010). Guided by the Uses and Gratifications (U\&G) theory, this study explored gaming pleasures and specific gender identities in WoW among Chinese players.

As an influential theory, $U \& G$ is an audience-centered approach, which assumes people actively seek media to gratify their social, psychological, and cultural needs (Blumber \& Katz, 1974; Merhi, 2016). With a long history in media research, $U \& G$ theory explores the gratifications that attract and hold audiences to the kinds of media and the types of content that satisfy their needs or wants; gratifications have been conceptualized as the utilities that explain media choice by consumers (Blumber \& Katz, 1974). There is no single or fixed list of gratifications obtained from media use; instead, multiple lists, categories, and classification systems were used in previous $U \& G$ research, with variables like arousal, acquisition, pleasure, escape, relaxation, and pastimes being used as references (Blumber \& Katz, 1974; Charney, 1996). MMORPGs are based on digital technologies, which can free human beings in virtual imagination. The world in a MMORPG is a place for immersion in pleasures, for experimenting and role-playing, and for the staging of dreams, wishes, fantasies, and desires (Crowe \& Watts, 2014; Kaye, Kowert, \& Quinn, 2017; Sundén, 2003; Martey, StromerGalley, Banks, Wu, \& Consalve, 2014).

Previous U\&G research has highlighted the significance of media use in identity expression (Leung \& Wei, 1998, 2000; Ostman \& Jeffers, 1983). Communication technologies are one of the crucial tools recrafting our bodies and identities, and the pleasures usually lie in the process of making meanings and forming identities (Fiske, 1987; Haraway, 1991). As a kind of popular and mainstreaming entertainment, MMORPGs seem open to all who want to have a try in gaming. The use of realistically modeled and animated humanlike avatars (virtual characters) has become the theme of multiple-user immersive virtual worlds, as it provides believable appearance and realistic movements, and the participants of collaborative virtual environments can use avatars to interact with the contents of the world and to communicate with one another using text, audio, video, and graphical gestures (Jiang \& Huang, 2013). Certain questions arise from these traits. How do players move between different characters within the game? Will the gaming practice free people from gender relations in the real world? In previous studies, information communication technologies (ICTs) are regarded as 
an ambivalent factor for gender identities in cyber space (Elm \& Sundén, 2007; Green \& Singleton, 2013; Leach \& Turner, 2015; Xinaris, 2016).

MMORPG playing is continuous, thus many players stay in a game for months and even years. The background story of WoW revolves around western wars and battles, full of fighting and killing, which is typically regarded as characteristic of a masculine genre (Roy, 2015). The images and narratives are mainly designed to meet male interests. This gender-bias may provide both freedom and restriction for players' identity-expression. Therefore, this study paid special attention to Chinese WoW players' gaming pleasures and gender identities in their gaming experiences.

\section{Methodology}

The study uses ethnographic methods to depict players' gaming experiences. As a WoW player, the author logged onto the game daily during the research period, and performed extensive participation in online gaming activities and interactions with other players in cyberspace, as well as in offline gatherings. Indepth interviews were conducted, including eight face-to-face interviews, four telephone interviews, and ten online interviews. The informants were all WoW players. By meeting some players face-to-face, the author had the opportunity to observe how they communicate and interact in real life, which cannot be obtained online, and also tried to link the virtual world to the real world.

However, these players cannot be regarded as representative of the way in which WoW is consumed in general, nor of a specific social category (women or men). This study is not based on quantitative demographic distribution of game playing, but rather attempts to show how players experience pleasures or displeasures in $W o W$. There are many ways of enjoying $W o W$, based on various understandings of WoW, but this study mainly dealt with the issues of gaming pleasures and gender identities, which are needed in the emerging field of game studies in China.

\section{Findings}

\section{Playing with Single Gender, Both or In-between?}

When playing the game, players face different choices for their character avatars, including faction, race, class, profession, gender, etc. Among them, virtual gender is the most interesting one. Based on the interviews, an embryonic typology was formed as below:

\begin{tabular}{llll} 
& & \multicolumn{2}{c}{ Player's gender in real life } \\
Avatar's gender in WoW & Male & Male & Female \\
& Female & Ladyboy & $\times$ \\
& "Neutral" & Neuter & Real lady \\
& Both & & $\times$ \\
& & & Experimenter
\end{tabular}


Based on the interviews, male players who only play male avatars are labeled "True man", while those who only play female avatars are called "Ladyboy", and those who only play neutral avatars are named "Neuter." Regarding female players, those who only play female avatars are called "Real lady." Both male and female players who choose both genders for their avatars are called "Experimenter." However, in this study, female players only playing male or neutral avatars were not found.

Sticking to one's true gender: "true man" and "real lady". Players who choose the same gender as theirs in real life usually play their character avatars in first-person view. There are some male players who only play male avatars. Some of them are averse to being labeled as ladyboys, while others seem to care less about avatars' appearance.

I have so many avatars, a Tauren Shaman, a Dwarf Hunter, a Troll Hunter, and a Tauren Druid, er, all male. Actually, I don't want my classmates jeer at me as a ladyboy. I always play with them. (Leo)

I don't have any female avatars. I don't play as a ladyboy, ho-ho. (Simon)

Female avatars have to be pretty, but for male ones it doesn't matter. All males are handsome, haw-haw! For some races, like Orc, Troll, and Dwarf, ur, are too ugly. Nobody would like to choose female characters from those races, so they are all male. (Daniel)

All the interviewed female players had their female avatars, and most of them only chose female as their virtual gender. It seems that females are more likely to keep their real gender identity in gaming practice.

I don't want to try any male avatars. I am female, so I chose female characters. (Jenny)

I never think about playing with male avatar. I just love my female characters. (Sarah)

The male ones? I think they are all ugly. Even though the human males are barely acceptable, I still pish away them. Not only me, I think even the designers also look down upon them. All the items are look nice on female avatars, but turn very disgusting on the male ones. (Linda)

Switching gender: "ladyboys" in WoW. It is not hard to understand that some players choose gender for their avatars according to their own identity, for consistency's sake. However, some male players only play female avatars. These players are called "Ladyboys" ("Ren Yao" in Mandarin).

Although the meaning of "ladyboy" is still to a certain extent negative in Chinese culture, WoW players show a more tolerant attitude towards the ladyboy phenomenon in the game. By choosing a female persona, male players can have some female experiences, which also bring them more fun, but they usually clarify that they do not use female avatars for benefits.

Many of my friends and I are all senior ladyboys. You know, female characters are beautiful. In the Alliance, there are too many female avatars, so no matter what you choose, no one will believe you are a real girl. (Shawn) 
Watching my female avatars is a feast for eyes. When someone calls me a beauty, I will tell him that I am not a girl. I don't like deception. I don't need any special privileges, either. (Daniel)

I am not satisfied with the male avatars in WoW. They are unsightly. That's why I chose female avatars. But players around all know I am male. And I play well, haha. (David)

All my characters are female. Okay, I am a ladyboy, but I never pretend to be a female player! I won't cheat for money or trifle with affections, or do any harmful things. Many people mistake me for a girl, maybe because of my personality. I've got a mild temperament. And I am a man of subtle and refined sensibility. That's why there are some misunderstandings. I'm tired of clarifying it. If they want to guess, it's their business. In a word, the rumor stops when it comes to a wise person. (Sunny)

Sunny is a special player, who even chooses a female profile for his QQ instant messenger. With female profiles and text-only online conversations, it is quite hard to believe he is actually a "he". To his male player-friends, his grumbles about being mistaken for a real female sometimes sound as if he is showing off. Some scholars argue that virtual gender is freed from the real physical body in text-based online worlds (Sundén, 2002). In a Multi User Dungeon (MUD), language is the only thing there is, so language and gender become mutually constituted and may even be interpreted as the same thing (Sundén, 2002). While different from text-only spaces like MUDs, voice chatting systems draw virtual gender back to the physical body, though some players still prefer to be typists in order to hide their real sex.

The label of "ladyboy" seems not to bother male players that much, especially when they are already good players. However, for female players, things are different within the game full of male players and ladyboys.

Ladyboys are so many, ubiquitous. (Jenny)

We all know that female players are much fewer, and most of the female avatars are played by male players. There are too many ladyboys in $W o W$, and they even don't disguise their identity as ladyboys, because it won't help and also cannot pretend long. People usually don't believe the female characters are real female. It is very common to be asked about the real sex, because the female avatars are too many. (Leo)

What I chose are female avatars, but sometimes it is ridiculous that other players ask me why I choose the female avatars as a male player. (Bonnie)

Of course, when I meet female avatars in the game, I always treat them as ladyboys. Real female players are rare, you know. And usually I don't ask others whether they are male or female. (Daniel)

There are so many ladyboys in the game that people won't believe you are real girl. Many boys choose female avatars, but cases in the other way are very few. The male characters are really unhandsome, while female ones might be taken care of in the game. (Celia)

I think the privileges are only for the girls who have been identified as real females, haha. As you know, too many ladyboys here. (Sunny)

Ladyboys are quite common, so I barely feel it. For me, when being mistaken as a ladyboy, I just acquiesce. While I won't specially pretend to be. (Nancy) 
Playing in-between: "neuters" of no genders. Although all the races in WoW have two genders, male and female, some races, mostly from the Horde, are treated as neuter or inbetweeners by the players.

I mainly play the avatars of Undead Warrior and Orc Warlock. Oh, my characters are male, but I think it's hard to tell the gender with the clothes on, or maybe because I'm in the Horde. (Mark)

I think Undead and Blood Elf are inbetweeners. The features and bodybuilds are similar between two genders. You know, for other races, at least are far apart in body type. (David)

Actually, in the Horde, gender differences are not that obvious. (Leo)

Some races are even representative of asexuality for most players. These desexualized features also arouse some strong feelings. Some players think they are annoying, while others derive some pleasures from them. These features can offer a challenge or a threat to dominant definitions of femininity and masculinity among players (Fiske, 1989).

The races like Tauren are not in the shape of human being. The races at least should look like human beings, then we can talk about genders, right? (David)

I think Taurens are of no gender. And also the Orc, because the so called female Orc looks just too ugly. (Jenny)

Definitely the Orc! Orc females are ugly, while I think it's euphemistic by using "ugly", aw, they look so disgusting. (Shawn)

I think the Blizzard takes care of these races. They may look neuter, but they have powerful talents. (Daniel)

Sometimes we make fun of them, like Tauren females. (Bruce)

I think it's Tauren, especially Tauren females, quite a shock. Tauren males are terrible creatures, too bulky. I am shocked when they appear. I have to kill them when I meet them, because we belong to opposite faction, but I always feel they are funny. I am wondering why Tauren females have boobs like that, ha-ha-ha. By the way, the tail and horn of Draenei are amused. (Nancy)

Trying both: "experimenters". The open secret about the real sex ratio in $W o W$ is that there are far more male players than females. Despite the situation of extraordinary disparity, players can choose both virtual genders if they want. In $W o W$, there can be many characters under one account, so many players choose to play both virtual genders.

Having male avatars, male players seem to feel less pressure around being ladyboys in the game.

I have two avatars. One is a male Dwarf Mage, and the other is a female Draenei Shaman. For the male avatar, I chose to be a short one, because I am tall, maybe because of the negative mentality, haha. For the other one, I just want it to be different, so I chose a female one. And it really doesn't matter. All the people know I am male. (Gray)

I like trying different characters, so I have quite a lot of avatars. The first is a male Dwarf Warrior, and after that one are all ladyboys, ho-ho. I think I prefer 
female avatars. You know, I am a role-playing type. I am not that involved and my items are not quite good, so nothing to it, actually (Daniel).

My female avatar was created after the male one, and both of them are on the same server, so basically they all know it's me. And I don't expect any privileges, because I can take care of my avatars very well on my own. (Bruce)

Compared with so many ladyboys in WoW, tomboys are quite rare. Most female players even do not think about male avatars as a choice. Some might try them occasionally, but still do not play with them very long.

I have a male avatar in stock, but I rarely play it. My boyfriend has a female avatar of Blood Elf, and I really want a lover-character, so I chose the male one. Usually, all the avatars I created are female. The male one is just a special case. (Jenny)

I think it's interesting to impersonate the opposite gender. I tried several times by using my boyfriend's male avatars. However, the male characters look so silly. Look how ugly Human and Night Elf males move! Ur, the Human males are the ugliest in the world. Oh, all my own avatars are female. (Nancy)

Female players may be relatively rare in $W o W$, but there are plenty of female avatars. Actually, almost all MMORPG players know that an avatar's gender might be in direct contradiction to the real sex of the player. Therefore, there are ways to test players' real gender. Especially during guild activities, voice chatting is usually required. Female voices can be heard during guild activities now and then. It seems that female players are not that rare, and there always several of them in every guild.

Most of us are in the same city, so we can get together frequently. I remember the two biggest ones, almost all the players in our guild came, we had dinner, and then sang at a karaoke bar, and still all in all we wanted to had a look at the female players in the guild, ha-ha! There were about 30 of us, only 5 girls, and 3 of them were girlfriends of the male players in our guild. (Simon)

It depends. In our guild, there are actually quite a few female players. When we have parties, $10 \%-20 \%$ are girls. (Mark)

Female players are still minority group in WoW. I think there might be only $2 \%$ of all the players. (Nancy)

I have been to players' party twice, definitely boys' party. (Bruce)

\section{Playing Like a Male or Female?}

Issues about real sex and virtual gender can be very complicated and confusing in $W o W$, but there are always clues and traces after close observation. Besides the choices of avatars' virtual gender, male and female players are usually different in their breaking-in processes, interactions and gaming styles.

Breaking-in process: it has something to do with technology. During the ethnography in WoW, I did not come across any female players who are self-invited, in other words who decided for themselves to play the game. Although many male players are also invited by their friends, some senior 
players have played WoW from the very beginning when it was introduced to the Chinese market. They are fans of Blizzard games and have already played Warcraft series before. Among the informants, Daniel, David, Mark, Shawn and Sunny are this kind of player. They were among the first to experience the breaking-in process, and later become experts in the game.

I played Warcraft III before, so WoW is familiar to me. I think newbie have to go through a hard time, but when I was a newbie, all the others were the same, so it's OK. I think it's harder for girls, you know, WoW is kind of masculine or macho style, and complicated, not for female players who are not used to action games. (Shawn)

According to my experiences, it takes longer to run in than other online games, but if you are really interested, it won't be too hard. After all, online games are of no advanced technology. (Mark)

WoW is mainly for male players, while females had better play causal games. It can ruin your pleasures when coming across someone's gaming skills are so poor. Well, if they are female players, people are more tolerant. (Daniel)

$\mathrm{Er}$, for girls, it's sort of hard to play. I think girls like casual games, with fewer complicated skills. At least, I haven't met any female master-hand. You know, compared with other games, WoW is of advanced technology factors. Well, it's up to personality, and there also can be some girls like technological things. (David)

Similar with other Blizzard games, it is not hard to pick up the basic skills, but you need time and effort to be a master-hand. For those who have played other MMORPGs before, the basic mechanism can be understood by a process of inference. However, for those who try MMORPG for the first time, it requires a lot of time. Actually, it is time-consuming for all the players, and nobody can play well without spending hours in front of the screen. It can be frustrating when players cannot play well, so one has to try to raise levels and devote oneself to gaming, sometimes losing sight of things happening at one's side, even things within the game. For example, choosing to be a Priest, during a quest in raid dungeons, means that the blood-bars of forty teammates can fill your eyes throughout the night and you can be too absorbed to pay attention to the appearance of the boss. With this kind of effort, a player will go through the breaking-in process gradually, while there are personal differences that seem to have little to do with gender differences. However, there is still gender-biased imagination within this masculine game genre.

I played kinds of online games before, so it's not hard to pick it up. Well, for girls, it should need more efforts, if they want to play well. Certainly, there are also some good female players, I know some in the game. But I find some female players both funny and annoying, they are slow-reacted, and attract monsters recklessly. Some angry-youth will get mad, but most people accept these mistakes kindly. Girls need more understanding and care. Well, girls in the game have many vantages and it's quite common. They are more inclined to ask for and get help. But we males usually play on our own and try not to bother others. (Bruce) 
Frankly, there are many female players who are really terrible at playing. You can tell they are girls at first glance. They are bad at controlling the movements, walk charmless, and keep adding or extremely slow-reacted. (Nancy)

It takes me quite a while to pick up the skills. I think it's harder for girls. Usually boys have better technology-sense. And it's a western game. The background stories are quite different, you know, kind of cultural differences. (Sarah)

$W o W$ is not an easy game, and not quite suitable for girls, kind of violent, and also complicated and demanding, not good-looking either. I find many female players know so little about the game, but they seem also enjoy a lot. Well, you cannot ask for too much from female players. For example, it's good for a girl to survive and keep the blood in raid dungeons. Don't expect too much. (Leo)

On the other hand, there are also many players who hold the view that males and females are equal in gaming, especially the female players who can play well. These players believe that WoW is not just a world for males.

It has little to do with gender differences. Girls can also play well. Don't look down upon female players. (Gray)

WoW has a high doorsill. I spent two months to get through, but it took half a year to truly understand how everything works, but I don't think it's only girls' problems. (Nancy)

I am kind of slow at the very beginning, but it's my problem. If I could make any changes, I would add more exacting tasks across the game. Now it's easy to get the best items. (Emma)

After studying intensively for several days, I could manage the basic skills. Many details can be explored later, or ask others. There are instructions for the professions. Just have a try. I don't think it's hard. If you have someone as a guide, it can be very easy. But if you want to figure out everything, it takes time. (Jenny)

It's easy, because I have played other online games and are used to the gaming atmosphere. I played Counter Strike (CS) before, so I am comfortable with 3D games - I won't feel dizzy. You can play well as long as you take it serious, but girls usually won't concentrate on gaming, hah, an interesting paradox. (Linda)

Interactions: PvP, PvE, RP and even offline. The Internet is described as a site for interaction (Hine, 2000). As a MMORPG, WoW is full of interactions with other players, or the gaming world, including non-player characters (NPCs), monsters, etc.

Within a game for people to become heroes, there are always acts of heroism. Male players usually offer kinds of privileges for females, but only for the real women, because there are too many ladyboys in the game. Female players are aware of this, although some might not take advantage of it.

I think $W o W$ is more suitable for male players, but females have their advantages - they are very popular and easy to get help. You cannot miss the moment when there are females in voice chatting, hah, male players swarm like bees. If the female voice is sweet, the males are unable to say no to her seek of help. Many times, some men can be like that. Anyway, girls always have privileges in WoW, especially beautiful ones. (Simon) 
Not very special, but the female players we know are certainly very popular (Mark). If you cannot play well, someone may ask whether you are a girl, you know, kind of disdain, but if they find you are really a girl, they turn to be very nice. (Celia) Many male players try to find out your real gender, then they will invite you to play with them, or chat with you, but some can be very annoying, keep talking. People are usually very nice to girls, for example, sharing loot. (Jenny)

Relatively speaking, female players enjoy some special treatment, not much, but, yeah, it's true. But I usually don't disclose my real gender. When asked, I always ask back: what do you think? (Sarah)

I have better items and skills than many male players, so I don't need to be taken care of, but I do receive many gifts, ha-ha. (Nancy)

Although both male and female players may enjoy the pleasures of PvE (player versus environment), which is a gaming element all players go through, male players seem not satisfied with only fighting and killing various monsters. A player cannot claim to be a master-hand if he has never tried PvP (player versus player) combat. $\mathrm{PvP}$ is one of the fundamental aspects of $W o W$, including fierce struggle between the Alliance and Horde in Battlegrounds, the competitive, fast-paced world of Arena combat, and the potentially massive conflicts of World PvP. The element of human intelligence, skill, and unpredictability when facing other players instead of computer-controlled enemies is one of the main draws to participating in $\mathrm{PvP}$. That is why many male players regard $\mathrm{PvP}$ as the main source of pleasure in $W o W$. In addition to the thrill of battle itself, which is its own reward, the victors can earn material rewards, such as powerful weapons, armor, and other items purchased with Arena points and from the Honor system. Therefore, some female players also become fans of PvP. However, to enter arenas, a player has to reach level 70 first, which means arenas are not for newbies.

PvP is my favorite and it's really full of fun. I even hope there can be more kinds of PvP. (Shawn)

I spend most of time on PvP in WoW. PK (player kill) is really a thrill. (David)

Most of time I am in arenas. Thanks to the arenas, WoW can have long vitality with the matches like Warcraft III. I will feel unhappy if I lose many rounds. There are few female players in arenas, after all most girls don't like fighting and killing. Well, the girls in arenas are honorable. (Sunny)

Maybe because there are differences between men and women, we like different things. My husband is very interested in fights in arenas and battlegrounds, and PK, while I am peace-loving. (Bonnie)

Quite a lot of WoW players regard PK in the open as the most exciting aspects and their only pleasure in the game, because all is unpredicted. PK is boys' favorite, and my boyfriend is of that type. I don't like PvP, but fight and kill everyday, and share the same language, I feel myself becoming neuter more or less. (Nancy)

I am a fan of PvP. Before reaching the highest level, PvE maybe good enough, but after that I find PvP is definitely more interesting - killing is really the best practice for skills. Those who keep following male players are just not professional, good female players won't act like that. (Linda) 
I like playing in arenas. After playing for so long, raid dungeons and battlegrounds are not exciting any more, but fighting in arenas is really stimulating. I don't mind if you regard me as an unorthodox type, hah, I like this kind of things. From this point of view, I am not really a lady. (Sarah)

The magic of a role-playing game is that players can always turn the gaming into their own style. Some female players act like newbies, others might play like males, while there are still some who change $W o W$ into their personal playground. With more attention, you can sense the differences between their chatting styles and gameplay. It is usually more relaxed with some girls as teammates. For example, when questing in raid dungeons the atmosphere can be full of tension, but if there are some female players, males might banter with them.

In WoW, there are two types of professions, primary and secondary, and all fall into three categories: gathering, production, and service. Every player can have as many secondary professions as he/she wants, but will only be able to choose two primary professions. For female players, many pay more attention to the secondary professions, like fishing and cooking, or business skills, caring little about their proper duties and business, which usually puzzles male players who are busy completing quests or fighting for something.

I lounge around in WoW most of the time, also fishing and mining, or chatting with friends, well, I don't expect anything. Oh, I do show off around, when I get something good. (Emma)

Recently, I am busy in raids, for better items. I like my avatar as a hunter, because I can keep a pet. I don't like PK, although girls are always popular in the game, when facing the opposite faction, they don't care whether you are a girl or not, someone just like killing so much. (Celia)

Maybe it's a masculine game, but we girls can always choose to play it in our ways. At the very beginning, most of the time just about to raise levels, I really don't like it, so sometimes my boyfriend takes care of it for me. I usually do those interesting things, practicing business skills, earning money, spending money, fishing and cooking, etc. After reaching the highest level, I just spend all the time doing these causal things. The biggest pleasure in $W o W$ is experiencing this kind of leisure. (Jenny)

I find playing with petty-characters is most interesting. I enjoy the great sense of achievement and also can help others. I hate those who bully petty-characters, and those who always think about melee, and I don't like swashbuckler, either. If only the pets in WoW could be electronic pets, ha-ha. (Sarah)

I prefer playing by myself, you know fishing, cooking, or rambling around the territory under the Horde's control, exploring the landscape and enjoying the views. Sometimes, it also can be dangerous, but I usually have my bodyguards around. Provocations between two factions can also be very interesting. Actually, I like the big events for both the Alliance and the Horde. It can be very interesting when lines are blurred, feeling that there are no enemies forever. There are festivals of this kind, but only on very rare occasions, because only the two factions on the whole server join forces together can make it. I wish there can be more this kind of celebrations and events. (Nancy) 
Female players are so fascinated by these kinds of interesting things, some even move from online to offline activities. Bonnie is still happy about the gift she got for her coming baby.

I like participating offline activities of WoW, always can get various good stuff, like toys or clothes, really exciting. Now it's in the period of celebrating Children's Day, I got a Brightly Colored Egg. I also like watching the touching and funny videos about $W o W$. Our guild hold get-togethers, too. We know one another in the game, we chat online, then we find out we are actually in the same city, when it comes to a certain number, we get together and know each other face to face, usually dinner first and then Karaoke, 2 to 3 times a year, mainly on holidays. (Bonnie)

No matter whether a player is of the role-playing type or not, the avatars represent them in the game. From low to high levels, players spend quite a long time with their avatars, and also use them to socialize in the game. For most players in $W o W$, it is important to look good. Players might use their look to control their relationship (Fiske, 1989). Therefore, image becomes one of the main sources of gaming pleasures.

As a Western game, the design and features are not quite in line with the tastes and values of Chinese players. Some female players mentioned that at first they were very reluctant to play $W o W$, just because the characters are not beautiful enough to meet their requirements. Although female players are usually particular on this, it seems that all the players have this kind of experience when facing this foreign game with cultural differences.

The western taste doesn't cohere with ours. Let me put it in this way, the features and movements are not easy to be accept by most of the people. (Sunny)

The Human females are not in accordance with our Oriental females. The overall look, including the Human males, is not of eastern style. They look a little strange, let alone Dwarves and Gnomes. Well, I think female Night Elves are $\mathrm{OK}$, tall and slim. (Linda)

As for the body shape, I think their breasts are overdone quite a lot. That's why so many ladyboys in WoW. (Nancy)

The Human females look kind of too plump. (David)

According to our tastes, the characters in WoW are not quite good-looking. They look very westernized, but their movements are very real. When I picked up my characters, I had no idea about the game, and only the Human females look acceptable to me. In WoW, basically females look better than males. Well, it is a game with no handsome male characters, for example, the movements of male Human Warlocks and Mages look very wretched. (Shawn)

I play the Human Mage, but the Human male looks a real bruiser. It's hard to imagine that character with so sinewy limbs, should at least look gentle. (David)

Every player can be very choosy when picking their avatars. Good-looking ones usually win players' favor. In this way, WoW offers its players access to semiotic and social power, which at the basic level works through fantasy (Fiske, 1989). Female characters are always the focus of attention. As a MMORPG evolved from Warcraft Series, which are considered masculine games, $W o W$ is still designed for the male gaze, or produced by the masculine look at 
the female body (Mulvey, 1975). The female characters are, to a certain extent, the sex objects within gaming, in accordance with the male imagination, though maybe of western tastes. Female players, who usually cannot accept ugly characters, have to get used to or accept the aesthetical standard from a male angle, although some may mock the masculine reading of patriarchy's conventions for representing women (Fiske, 1989).

I care about the appearances, absolutely. Good-looking is the kingcraft. (Shawn) The most important is to look good. (David)

Of course, the characters have to be beautiful! Female Night Elf is sexy, but the face is not pretty. Well, the Human girls are better. (Daniel)

Being pretty is my standard to choose characters. Well, all the female characters in WoW have that kind of big boobs. (Jenny)

I'm in the Horde. All the characters are not beautiful. Now, I have get used to these, but if I could make any changes to WoW, I still want characters in the Horde could look pretty. (Bonnie)

I chose the Human warrior, because I think she looks, how to say, more like a human being in real life. (Emma)

As for those ugly races, few people will choose the female characters, even uglier. (David)

Actually, I once wanted to try some, like female Orc Rogue, quite rare and would be special, but finally gave up. It's just too ugly for me to face it. (Bonnie)

This sort of empowering fantasy is pleasurable to the extent that it can, under certain conditions, constitute the imagined possibilities of small-scale social change. It may provide the motive and energy for localized tactical resistances (Fiske, 1989). Although many players prefer good-looking characters, other characters are not totally turned out in the cold. There are still some players who choose them for various reasons. Except for races, there are different classes for players to choose, including Druid, Hunter, Mage, Paladin, Priest, Rogue, Shaman, Warlock, and Warrior. Each race has certain playable classes and unique racial traits. These options of different attributes are used to equip gendered characters, and also to cover the shortage of some bad-looking ones.

My characters are all from Warcraft III. They look familiar to me. (Mark)

Female Dwarves are cute, with big heads and plaits like candy-floss, and their voices are sweet, too. They are very funny, exactly the type for "Loli (Lolita)" style. (Sunny) Usually, people like beautiful characters, while there are always some people who want to be different. Actually, my avatars look not good, for example, male Dwarf Hunter. I think Dwarf corresponds with the prototype of hunters, and the dwarf looks simple and honest. But I regret it now, he, nevertheless, looks not good. (Bruce)

My character is male Human Rogue, yeah, not good-looking, but easy to get to higher levels, so many starters choose this one. I think all male characters are ugly, only items make the differences. Dressed up in good items is the best appearance. (Simon)

One of my characters, the female Human Rogue, looks like me very much. Well, that's not interesting. So I try a female Dwarf later. Long live the Dwarves! They might not look that pretty, but have very powerful racial traits. The Internet is for people to realize the impossible things in real life, isn't it? (Nancy) 
Being in the Horde, the players actually don't have many choices. The characters are all ugly. Tauren males I chose are not that bad among them. Sometimes, I pay more attention to the skills and even forget the appearances. In a long period, I almost forget what my Tauren Shaman looks like, only his back and helmet. After playing for a while, you will like your avatars, no matter what they look like. And I don't think players of opposite faction will care about your appearance. (Leo)

My avatar looks not pretty, although Troll females look better than others within the Horde, so I practice fishing and cooking, and I can entertain others with delicious snakes. (Bonnie)

The appearances and movements of good-looking characters can offer players pleasures, but what about the ugly ones? Some players find them funny, but mostly ugly characters become the targets of attacks, which are also an important source of pleasure.

My avatars are female Human Paladin and female Night Elf hunter. At the beginning, I knew nothing about the game, so I only cared about the appearances. I know female dwarves are cute, but between the cute and beautiful ones, I will choose the latter. I don't like Undead, Orc or Troll, even detest them. You know, I will unconsciously attack these races first in battlegrounds. (Sarah)

The male Troll and female Tauren are so ugly, but some players do choose them, playing the devil's advocate. For me, I just want to beat them when I meet them, as long as it isn't outnumbered. (Gray)

Gaming style: play as a lone wolf or in groups? When first entering $W o W$, all players face the question of what race to play when creating a new avatar. WoW offers ten playable races, which are Dwarves, Gnomes, Humans, Night Elves, Draenei, Orcs, Tauren, Trolls, Undead and Blood Elves. These races are further divided into two warring factions: the Alliance and the Horde. Draenei, Dwarves, Gnomes, Humans, and Night Elves form the Alliance; while Blood Elves, Orcs, Tauren, Trolls, and Undead belong to the Horde. Although there seem to be plenty of choices, there are also rules that reduce freedom. Characters can only talk, group, and create guilds with players from their own faction. Certain zones and cities in the game are also friendly to one faction, while hostile to the other. Additionally, certain quests can only be completed by members of one faction and not the other.

In $W o W$, it is also usually the case that many friends try to play together. New players often choose one of the factions by following their friends who are already in the game. Some players even make their group decision to play and grow together in the game. After reaching higher levels, players may feel comfortable and get used to the faction they choose. Even in the virtual world, decisions about new identities can be collectively made, moreover, according to certain rules.

At the beginning, I just followed my friends to the Alliance. (Sarah)

Those who I know personally all play within the Alliance, so I chose the Alliance to play with them together. (Emma)

I chose the Alliance mostly because of peer influence. All the friends around playing $W o W$ were in the Alliance, and I had no idea about the game at that time. 
Therefore, I asked them for advice. They told me the Alliance was good, so I just entered the Alliance. (Simon)

The friend who invited me into WoW played a human warrior. At that time, both of us were not familiar with the game, so we chose the same birthplace and played together. (David)

Choosing to play within the Hordes is the decision of our guild. (Mark)

This rule is definitely for gaming, but it also can be a limiting factor to the mobility of players' identities. Some players may not like this clear-cut distinction, but they have to make a compromise to enter the game. This kind of decision annoys the female players more, mainly because races of the Alliance are in the shape of human beings, while the Horde are mostly not.

Actually, I was forced to choose the Horde. When we moved to this new server, I really wanted to try the Alliance, but they all chose the Horde, so I chose it, too. Whoever dare censure me as a traitor? I will kill him! (Bonnie)

My boyfriend chose the Orc. I know the Alliance look better, but I have to be in the same faction with my boyfriend. As you know, once a player gets used to on faction, it is hard to switch to the other. (Jenny)

In fact, I wanted to play within the Alliance, because I like the better-looking ones. However, my friends wanted to play the Horde, so I have to be with them. Well, races in the Horde seem to be more powerful, maybe because they are so ugly. (Leo)

I think those who choose the Horde are tartarly male players, while many female players on new servers choose the Horde, too. Well, you have to accept the situation that avatars in the Horde have eccentric images which might meet the taste of new player generation. Those only in pursuit of strong power also choose the Horde. (Sunny)

The Alliance on our server is stronger, so my boyfriend and I chose it. In fact, I really like female Tauren, so cute, you know, the face looks so innocent, and the body is plumpy. If a female Tauren does striptease in front of me, I will hesitate to kill her. While I think I still will kill her, anyway we belong to two opposite factions. (Linda)

Sometimes, I think female Undead looks nice. However, a player cannot choose races from both of the two opposed factions on the same server. My friends all play the Alliance, so I finally did not choose Undead, and even do not try any race from the Horde. (Daniel)

The axiom in $W o W$ is that there is strength in numbers. According to the ethnographic experience, $W o W$ is not the world for a lone wolf. Players usually play with others, and this is also one of the main differences between online games and PC games. There are different kinds and sizes of groups in WoW, namely group/party, raid, and guild. A group or party can have a maximum of five players. Raids of up to 40 players can fight powerful monsters, wage war in PvP battles, and work with others to share loot, experience, and quests in raid dungeons. A guild is a group of players joining together for companionship, adventure, economic gain and more. Guilds offer many benefits, including free items, opportunities for groups, access to trade skill masters, quest items, and readily available trade skill ingredients through gathering guild members. 
In such a huge and challenging virtual world, companions are needed. Playing in groups may also greatly enhance players' gameplay experience. Typically, players in groups can venture into dangerous areas and do things that a single player cannot. Gaming in a group, players not only share adventures, but also make friends. The whole game, to a certain extent, is a graphic chatting room. Players chat with each other either through voice or text, from instant to instant.

I spend most of the time in raid. It's the tendency in $W o W$, and teamwork is very important. (Mark)

At first, I played on my own or with several friends, but later I find it wonderful to play within guild. We get along well with one another. (Simon)

Interaction and communication are important in online games. Playing a MMORPG all by oneself might be like playing a PC game. I think every player in WoW is in groups, while maybe of different kinds. Our guild is of PvP type, so most of us like battles. Therefore, it's more flexible and equal, and we are all friends, helping one another. (Sunny)

Fighting a lone battle won't work in WoW. Only within guild can players quest in raid dungeons. I usually try to participate in guild activities on time. (Leo)

Both male and female players take pleasure in participating in groups in WoW. Male players usually find it exciting and rewarding to fight in groups, while quite a few female players share the pleasures by putting themselves in male shoes. The pleasure of killing might not be enjoyed by all female players, but females can also find their way out, by striking up a friendship, or treating $W o W$ as a chatting room, certainly an advanced one. The experiences with people protecting them when fighting in faction-versus-faction combat are treasured by most female players. It is fascinating to wander about or camp around within the magnificent surroundings, and the feelings can be quite real.

Playing in guild is my favorite. Nothing can be more exciting than routing the tough monster boss in raid dungeon. (Sunny)

I feel a great sense of achievement when I can play quite well in the game. Playing in a good guild, you will feel great for everything. I remember the celebration for the first anniversary of our guild, all of us, about 150 players, went to attack the main city of the Horde. After the slaughter, the Horde were too scared to go back home. So cool. (Linda)

There is a lot of fun in guild. I find a great joy of chatting and teasing in guild. I treasure the friendship and solidarity, you know, all the members fight shoulder by shoulder making concerted efforts to kill a big monster, or the teammates cover one another desperately when encountering the Horde in the open. (Nancy)

Guilds can be like a box of chocolates, you never know what you will get. It is not hard to find someone sitting in town and inviting people to join their guild, because guilds require a minimum number of members to create. However, finding a high-quality guild with good-quality leadership and members can be a difficult task. Guilds are run by players, so the quality depends entirely on the players involved. Therefore, guilds are usually the source of both pleasures and displeasures. A newbie might find it quite demanding, and even feel repressed in guild activities. If interpersonal relations go wrong, it can be very troublesome, 
especially for those players who like PvE. Good or bad guilds are always determined by whether players can have fun or not.

I am under a lot of pressure when questing in raid dungeons. I always play Priest with rapt attention, healing and restoring the wounded, but there still some teammates die occasionally. Then someone may throw some harsh words, which caused me much pain. That's why sometimes I fear to join guild activities, lest I may screw up. I also hate someone is very full of oneself. And in battles, some players are just lack sense of duty, causing the whole guild lost. Aw, annoying! (Jenny)

When the guild gets bigger and bigger, there will be different opinions. Not all the members share the same goals, which can lead to many disputes in the end. For example, the DKP (Dragon Kill Point), because it is relevant to many benefits, sometimes can cause such a mess. Players are quite different. The guild, now I'm in, is for casual players. We just want to enjoy ourselves, and all other things are secondary. (Bonnie)

Some teammates just take advantage of the friendship, you know, cheating for items. And some always sacrifice the online friends in game to please the friends in real life. For these reasons, I gave up my Tauren Shaman, a character with great items and very promising. (Leo)

I am in a high-end guild. Sometimes the guild only keep after efficiency, so the new recruit cannot join the activities. Moreover, good and bad persons are intermingled in such a big guild, so there are also dirty words and cheatings, even stealing accounts. Horrible, isn't it? Oh, there are also some noobs fancy themselves as infallible, which I can't bear. (Nancy)

Few players play alone, even though it might not always be happy in a guild. There is another special phenomenon in the game - couple players. The dominant narrative of $W o W$ is becoming a hero, and there is no design like ingame marriage. Although a love story is not part of the main narrative in WoW, folks in the game are still allowed to give and receive tokens and gifts to others, expressing friendship, admiration, or love. The widespread occurrence of love stories is not unique in WoW. In fact, players can get married with a marriage certificate and impressive ceremony within many popular online games in the Chinese market. The nostalgic and ethnic imaginaries derived from the Confucian history are necessary elements of in-game marriage for most Chinese MMORPGs (Wu et al., 2010), which more or less have effects on $W o W$ players. Not all players in $W o W$ are willing to identify with this, but usually players have an open mind for the matter.

WoW is still very pure. Its popularity depends mainly on game-play. (Shawn) $W o W$ is quite interesting, not like some games are just for men to make advance to women. (Linda)

Some of them even call each other "husband" and "wife" in the game. Well, I don't hold any particular position on this issue, and I am accustomed to it after hearing a lot. (Gray)

In WoW, marriage can be in word only. It's no big deal, and is other people's business. Well, I will be pleased, if the persons involved are my friends. (Sunny) That may be people's personal liking - we can leave it at that. Such is the nature of gaming that it's unrestrained and players can play as they want. Marriage in 
games cannot be serious. You have no idea who are female players. After all, there are much more male players in this game. (David)

As stated earlier, and based on the interviews, hardly any female players come uninvited. They are usually invited by friends, and sometimes by their boyfriends. Therefore, couples in some cases just emigrate from the real world to the virtual world.

At first, it's because my boyfriend like this game so much. I played some other online games before, but considering we can play this together, I just moved into WoW. And we share our characters, playing them together. (Linda)

It's very hard to play alone in this game, so few female players are self-invited. Most of them play with their boyfriends or husbands in real life. (Leo)

It's not hard to find some players pair off and play together, and many couple characters in the game. Maybe they are real couples. Well, some of them might just get acquainted in the game, but won't many, you know, there are not many female players. (Jenny)

I guess those girls are taken care of by their real boyfriends. While some senior players told me that many great guilds were ruined because of female players, aw, femme fatales. (Daniel)

Falling in love within the game seems not to come easily, but it is not beyond reach either. Although those skeptical players are suspicious of the "love sickness" clouding the hearts of so many, some brave adventurers choose to ignore possible sinister plots behind the source of this plague of passion. Just like real couples can move into the virtual world, some virtual couples also have their wedding in real world.

There are also Internet love affairs in WoW, though not as many as those in the games with marriage mechanism. Without designed mechanism, players still can get married if they want to. I attended a wedding in WoW: in a scenic place, the couples dressed up in wedding veil and tuxedo, with their friends, watch the fireworks and various interesting items, and there is a marriage witness, too. The couples can hold their wedding creatively, because there is no official design. It can be ingenious and original, you know, many WoW players are Cosplayers, too. (Nancy)

Marriage in $W o W$ can be interesting. The weddings are usually in the guild. Some also take wedding pictures, the screenshots of the two characters in the game. It's hard to say. Some players come across each other in WoW, get married in the game and then get married in real world. (Simon)

I have some friends are couples in the game. They meet each other offline and fall in love, but I think it's not quite realistic, after all, players of WoW are from all over the country, so it's hard to be together. I confer my benediction to them, if they can make it. (Sarah)

Couple players are not that rare in WoW, actually my husband and I know each other in WoW. (Bonnie) 
Not every virtual marriage in the game can have a happy ending in the real world, because virtual gender does not always correspond with the real sex. There are a great number of ladyboys in $W o W$, which to some extent blur the line.

Getting married with a ladyboy, hah, it's hard to avoid, after all, nothing is impossible on the Internet. (Bruce)

There are so many ladyboys in $W o W$, so just bad luck for those who get married with ladyboys. (Sunny)

I think there must be ladyboys in marriage, but maybe the persons involved don't know that. They might not call each other husband and wife if they know that. (Gray) Some players just get married with very utilitarian purpose. Married with a master-hand can be rewarded. I won't get married in the game, while I don't mind others getting married. How can it be so many female players in WoW? You are lucky to come across one or two among 10 players. Many are just ladyboys. Some male players just get married with ladyboys. Tow heads are better than one, so over shoes over boots. (Simon)

In addition to these different relationships, WoW also offers some soloing classes, like Druid, Hunter, and Warlock. Therefore, some players can play alone, but players of this kind are quite rare. Emma is very special in WoW. If it were not for Leo, who knows Emma personally, it is hard to notice her in the game. She seldom talks, even textually. She is satisfied to amuse herself in the noise and bustle of gaming and just watches others.

I play WoW casually, and don't expect anything. I try to found my own guild, but don't invite anyone, only me in it. Well, yeah, I'm different. (Emma)

\section{Conclusions}

Nowadays, online gaming has become part of people's daily lives, and game studies have gained more importance in communication and media studies. While online games are popular, there are still many unfamiliar aspects for researchers. For example, pleasure as one aspect of popularity is in itself complex enough (Ang, 1985). This paper presented a qualitative explorative study, which applied a U\&G approach to explore Chinese players' gaming experiences within WoW, a worldwide popular online game, and investigate gaming pleasures as gratifications and the players' expression of gender identities.

Even though the U\&G approach has been widely applied to different media, it is important to consider gratifications from online games as a specific, newer, and more interactive media genre. It is in the actual confrontation between players and games that pleasures are primarily generated. The results reveal involvement and interaction as players' pleasures in WoW. The players get really involved, and their virtual life becomes integrated into their real life, no matter whether they are playing in first-person or third-person view. The game's mechanisms and design provide players with more choices of identity expressions, while the anchor of the real world still holds. For example, some choose their new avatars based on 
collective decision or suggestion; groups hold events online and offline; and love stories also take place in both online and offline worlds.

Consistent with previous studies, the findings also highlight the significance of media use in identity expression. Based on digital technologies, online game playing seems to afford great potential of rearrangements of race, sex, and class rooted in high-tech facilitated social relations (Haraway, 1991). With more userfriendly developments and improvements, these games help players of both sexes to realize their dreams in the virtual gaming world. However, gender identities in gaming practices are not as fully mobile or fluid as imagined, partly because of the restriction in the game, partly because of anchors to the material body in physical reality. The dominant narrative in $W o W$ is about the growth of heroes and is full of fighting and killing, which are basically masculine styles. Some female players choose to play as tomboys, becoming master-hands like males, while others derive pleasures of their own by consuming the game in alternative ways. In this way, players struggle and enjoy between rules and freedom, pleasures and challenges within the virtual world without an end. Moreover, in conditions of great disparity in sex ratio, real sex earns privileges for female players, and gender identities, especially for females, tend to be stabilized through interactions. Further study may examine the interrelationships based on quantitative data.

Another significance of this study is that it attempts to relate the foreign game settings with its cultural contexts and Chinese players' gaming practice. Evolved from Warcraft Series and retaining the war-story background, WoW is typically perceived as a game of the masculine genre with a Western background. Although most players of both sexes are not satisfied with the male characters, some races, or other western elements, many female characters are accepted. They are sexy with explicit sexual characteristics, designed from the male gaze, and partly acting as sex objects in gaming practice. That is also why there are so many ladyboys in the game. Female players who cannot accept the ugly images also have to choose their electronic persona like males. In this way, some stereotyped images are reinforced. Races with nonsexual features become another choice. Based on U\&G approach, this study provides more understanding of gaming experiences and identity expression in WoW. In the future, related gender-specific targeting strategies, user-centered design and content of Eastern features can be considered by game developers and designers.

\section{Acknowledgments}

Funding for this study was provided by Project 14CXW031 supported by National Social Science Foundation of China.

\section{References}

Ang, I. (1985). Watching Dallas: Soap Opera and the Melodramatic Imagination. Massachusetts: Methuen. 
Blumler, J. G., and Katz, E. (1974). The Uses of Mass Communications: Current Perspectives on Gratifications Research. London: Sage.

Charney, T. R. (1996). Uses and gratifications of the Internet (Unpublished Master's Thesis). Michigan State University, East Lansing, USA.

CNNIC - China Internet Network Information Center. (2009). The Marketing Research Report on Online Games in China. Retrieved from goo.gl/6uZvMG.

CNNIC - China Internet Network Information Center. (2017). The 39th Statistical Survey Report on the Internet Development in China. Retrieved from goo.gl/ ZJNkXw.

Crowe, N., and Watts, M. (2014). "When I click "ok" I become sassy - I become a girl". Young people and gender identity: subverting the "body" in massively multi-player online role-playing games. International Journal of Adolescent Youth, 19, 217-231.

Elm, M. S., and Sundén, J. (2007). Cyberfeminism in northern lights: Digital media and gender in a nordic context. Newcastle upon Tyne: Cambridge Scholars Publishing.

Fiske, J. (1987). Television culture. Massachusetts: Methuen.

Fiske, J. (1989). Reading the popular. London: Unwin Hyman.

Green, E., and Singleton, C. (2013). "Gendering the digital": The impact of gender and technology perspectives on the sociological imagination. In K. Orton-Johnson, and N. Prior (eds.), Digital Sociology. London: Palgrave Macmillan.

Haraway, D. J. (1991). Simians, cyborgs, and women: The reinvention of nature. London: Routledge.

Hine, C. (2000). Virtual ethnography. London: Sage.

Jiang, Q., and Huang, X. (2013). Internet: Immersive virtual worlds. In P. M. Miller (eds.), Principles of Addiction: Comprehensive addictive behaviors and disorders (pp. 881-890). London: Elsevier.

Kaye, L. K., Kowert, R., and Quinn, S. (2017). The role of social identity and online social capital on psychosocial outcomes in MMO players. Computer in Human Behavior, 74, 215-223.

Leach, L., and Turner, S. (2015). Computer users do gender: The co-production of gender and communications technology. London: Sage.

Leung, L., and Wei, R. (1998). The gratifications of pager use: Sociability, informationseeking, entertainment, utility, and fashion and status. Telematics and Informatics, $15,253-264$.

Leung, L., and Wei, R. (2000). More than just talk on the move: Uses and gratifications of the cellular phone. Journalism and Mass Communication Quarterly, 77, 308-320.

Martey, R. M., Stromer-Galley, J., Banks, J., Wu, J., and Consalve, M. (2014). The strategic female: gender-switching and player behavior in online games. Information, Communication \& Society, 17, 286-300.

Merhi, M. I. (2016). Towards a framework for online game adoption. Computer in Human Behavior, 60, 253-263.

Mulvey, L. (1975). Visual pleasure and narrative cinema. Screen, 16, 6-18.

Ostman, R. E., and Jeffers, D. W. (1983). Life stage and motives for television use. International Journal of Aging and Human Development, 17, 315-322.

Roy, D. (2015). Fighting heroic hegemony with ennui: The remarkable everyday in World of Warcraft. Journal of Gaming \& Virtual Worlds, 7, 169-181.

Sundén, J. (2002). "I'm still not sure she's a she" textual talk and typed bodies in online interaction. In P. Mcllvenny (eds.), Talking gender and sexuality (pp. 289312). Amsterdam: John Benjamins. 
Sundén, J. (2003). Material virtualities: Approaching online textual embodiment. Switzerland: Peter Lang.

Wu, J., Wang, S., and Tsai, H. (2010). Falling in love with online games: The uses and gratifications perspective. Computer in Human Behavior, 26, 1862-1871.

Xinaris, C. (2016). The individual in an ICT world. European Journal of Communication, $31,58-68$. 
Appendix. List of Informants and Some Detailed Information

\begin{tabular}{|c|c|c|c|c|c|c|}
\hline Informant & $\begin{array}{l}\text { Sex/ } \\
\text { Age }\end{array}$ & $\begin{array}{c}\text { Years in } \\
\text { WoW }\end{array}$ & \begin{tabular}{|c|} 
Marital \\
Status
\end{tabular} & Occupation & Education & $\begin{array}{c}\text { Personal Monthly } \\
\text { Income }\end{array}$ \\
\hline Bonnie & $\mathrm{F} / 26$ & 2 & $\mathrm{M}$ & $\begin{array}{l}\text { Housewife \& } \\
\text { Part-timer }\end{array}$ & $\begin{array}{l}\text { Bachelor's } \\
\text { Degree }\end{array}$ & Less than $¥ 3,000$ \\
\hline Bruce & $\mathrm{M} / 21$ & 3 & $\mathrm{~S}$ & $\begin{array}{l}\text { College } \\
\text { Student }\end{array}$ & $\begin{array}{l}\text { Junior } \\
\text { College }\end{array}$ & None \\
\hline Celia & $\mathrm{F} / 24$ & 0.5 & $S$ & Technician & $\begin{array}{l}\text { Bachelor's } \\
\text { Degree }\end{array}$ & $¥ 3,500$ \\
\hline Chris & $\mathrm{M} / 24$ & 2.5 & $S$ & unemployed & $\begin{array}{l}\text { Junior } \\
\text { College }\end{array}$ & None \\
\hline Daniel & $\mathrm{M} / 24$ & 1 & $S$ & Technician & $\begin{array}{l}\text { Bachelor's } \\
\text { Degree }\end{array}$ & About $¥ 2,000$ \\
\hline David & $\mathrm{M} / 25$ & 3 & $\mathrm{~S}$ & Civil Servant & $\begin{array}{l}\text { Bachelor's } \\
\text { Degree }\end{array}$ & $¥ 3,000 \sim 4,000$ \\
\hline Emma & $\mathrm{F} / 24$ & 1 & $\mathrm{~S}$ & Designer & $\begin{array}{l}\text { Bachelor's } \\
\text { Degree }\end{array}$ & More than $¥ 2,000$ \\
\hline Gray & $\mathrm{M} / 24$ & 2 & $\mathrm{~S}$ & Office Clerk & $\begin{array}{l}\text { Junior } \\
\text { College }\end{array}$ & About $¥ 2,000$ \\
\hline Jenny & $\mathrm{F} / 24$ & 1.5 & S & Part-timer & $\begin{array}{l}\text { Bachelor's } \\
\text { Degree }\end{array}$ & Less than $¥ 1,000$ \\
\hline Leo & $\mathrm{M} / 23$ & 2 & $S$ & $\begin{array}{l}\text { College } \\
\text { Student }\end{array}$ & College & None \\
\hline Linda & $\mathrm{F} / 21$ & 3 & $\mathrm{~S}$ & $\begin{array}{l}\text { College } \\
\text { Student }\end{array}$ & College & None \\
\hline Mark & $\mathrm{M} / 25$ & 3 & $S$ & Technician & $\begin{array}{l}\text { Master's } \\
\text { Degree }\end{array}$ & $¥ 5,000 \sim 6,000$ \\
\hline Mary & $\mathrm{F} / 24$ & 2 & $S$ & Secretary & $\begin{array}{l}\text { Bachelor's } \\
\text { Degree }\end{array}$ & About $¥ 2,000$ \\
\hline Michael & $\mathrm{M} / 28$ & 4 & $\mathrm{~S}$ & Freelance & High School & NA \\
\hline Nancy & $\mathrm{F} / 24$ & 2 & $\mathrm{~S}$ & $\begin{array}{l}\text { Graduate } \\
\text { Student }\end{array}$ & $\begin{array}{l}\text { Master } \\
\text { student }\end{array}$ & None \\
\hline Sam & $\mathrm{M} / 21$ & 3.5 & $\mathrm{~S}$ & $\begin{array}{l}\text { College } \\
\text { Student }\end{array}$ & College & None \\
\hline Sarah & $\mathrm{F} / 21$ & 2 & $S$ & Office Clerk & $\begin{array}{l}\text { Bachelor's } \\
\text { Degree }\end{array}$ & About $¥ 3,000$ \\
\hline Shawn & $\mathrm{M} / 25$ & 3 & $\mathrm{~S}$ & Journalist & $\begin{array}{l}\text { Master's } \\
\text { Degree }\end{array}$ & About $¥ 4,000$ \\
\hline Simon & $\mathrm{M} / 24$ & 0.5 & $S$ & $\begin{array}{l}\text { Graduate } \\
\text { Student }\end{array}$ & $\begin{array}{l}\text { Master } \\
\text { student }\end{array}$ & None \\
\hline Sunny & $\mathrm{M} / 23$ & 3 & $S$ & Technician & $\begin{array}{l}\text { Bachelor's } \\
\text { Degree }\end{array}$ & About $¥ 2,000$ \\
\hline Terry & $\mathrm{M} / 18$ & 3 & $S$ & $\begin{array}{l}\text { High School } \\
\text { Student }\end{array}$ & High School & None \\
\hline Yolanda & $\mathrm{F} / 20$ & 3 & $\mathrm{~S}$ & $\begin{array}{l}\text { College } \\
\text { Student }\end{array}$ & College & None \\
\hline
\end{tabular}

Note: In this list, pseudonyms are used to protect informants' privacy. M-Male; F-Female; SSingle; M-Married 
